\title{
Online Interaction among Students and Faculty: A Comparative Study
}

\author{
Plamen Miltenoff \\ St. Cloud State University, \\ Learning Resources and \\ Technology Services, St. Cloud, \\ MN, USA
}

\author{
John Hoover \\ Cloud State University, \\ College of Education, \\ St. Cloud, MN, USA
}

\author{
pmiltenoff@stcloudstate.edu
}

\author{
ihhoover@stcloudstate.edu
}

\author{
Galin Tzokov, \\ Paisii Khilendarski University, Department of Pedagogy, \\ Plovdiv, Bulgaria
}

g tzokov@abv.bg

\begin{abstract}
Based on recent proliferation of online education and ongoing technological revolution, this research focuses on interaction of students and faculty as a main contributor to the success of online education. A survey of 22 items was distributed to faculty members and students from the Midwest of the U.S. and 3 Eastern European countries during the period of 2002-2003. The data collected reflects students and faculty opinions about the state of technology and online communication. The results confirm findings from the literature about digital divide between developed and emerging countries.
\end{abstract}

Keywords: online interaction, library role, use of computer labs, state of technology

\section{Introduction}

A rapidly increasing number of online classes and programs prompt researchers and pedagogues to focus on online interactions. Interaction is the critical factor for students' satisfaction (e.g., Burnett, Bonnici, Miksa, \& Joonmin, 2007; Gould \& Padavano, 2006; Green, et al., 2005; Young \& Norgard, 2006), higher level of academic achievement (e.g., Bell, 2007; Lee, Carter-Wells, Glaeser, Ivers, \& Street, 2006) and higher level of motivation (e.g., Bennett \& Lockyer, 2004;

Material published as part of this publication, either on-line or in print, is copyrighted by the Informing Science Institute. Permission to make digital or paper copy of part or all of these works for personal or classroom use is granted without fee provided that the copies are not made or distributed for profit or commercial advantage AND that copies 1) bear this notice in full and 2) give the full citation on the first page. It is permissible to abstract these works so long as credit is given. To copy in all other cases or to republish or to post on a server or to redistribute to lists requires specific permission and payment of a fee. Contact Publisher@InformingScience.org to request redistribution permission.
Kawachi, 2003; Schrum, Burbank, \& Capps, 2007)

The existence of online environments is made possible by the technological revolution and the Internet's advent. The online environment thrives on and generates technological advancements; it offers alternatives in space and time-compared with traditional classroom environments. Therefore, interest has 
been expressed in exploring the effects of online spaces on teaching and learning processes.

The leaders in distance education included Pacific countries such as, but not only, Australia, New Zeeland, Canada, and the United States (Stephenson, 2002). This is not a coincidence. Countries of vast territories, sparse population and ability to invest in distance education are most likely to be ahead in the use of online interaction. Therefore, we accept, as benchmark data, results from students and faculty in the United States.

On the other side of the global spectrum are countries from the developing world, which fall behind, despite efforts such as the $\$ 100$ laptop initiative (http://laptop.media.mit.edu/) and similar projects aimed at bridging the digital divide (Read, 2007). For example, Bulgaria, Macedonia and Moldova enjoy proximity to Western Europe and thus connectivity to a well-developed Internet grid; yet they lag far behind European Union standards and requirements for hardware, software, Internet connection and usage. For example, Bulgaria is estimated to be a decade behind Western European countries and the Unite Stated in the process of building an information society (Report e-Bulgaria, 2006).

On the other hand, Eastern European academics manage to keep close, if not move abreast of their Western European colleagues in terms of educational technology applications. In order to bridge the digital gap, the Bulgarian government had promulgated several basic strategic documents, including one for e-education. In the period of 2002 to 2005, Bulgarian academic institutions funded over 250 computer labs; a large number of educational institutions in Bulgaria provide wireless Internet connection, thus initiating the transition toward mobile learning (mlearning). Bulgarian educational institutions have worked on the development of several in-house Course Management Systems (CMS) and about 15 distance education centers have been formed in educational institutions.

Such progress cannot overshadow the facts that in 2002, the computers/students ratio in the American University in Bulgaria (AUBG, http://www.aubg.bg/) was about eight times higher than the ratio at state institutions (National Evaluation and Accreditation Agency's Newsletter, 2002, p. 399). In the following two years the efforts increased (educational institutions equipped with schools and/or upgraded computers, Internet access, students' and faculty training, etc.). According to the National Evaluation and Accreditation Agency (http://www.neaa.government.bg), in 2005, the ratio improved to 8 computers per 100 students, from 4 computers per 100 students in 2001, yet overall, the technological state of the country is still far behind the European standards. Educational institutions also boosted their presence on the Internet and upgraded their Internet connection to broadband and wireless. For the same period about $68 \%$ of the higher education institutions used CMS and about 150-200 courses contained multimedia content.

\section{Data Gathering}

Considering the background above, this research was designed to answers to the following descriptive research questions:

1. What is the state of technology at educational institutions in Eastern Europe and the United States?

2. What is the level of knowledge and skills related to educational use of information technologies?

3. What is the degree of access to information technologies by faculty and students?

4. Do the above indicates difference by country?

The statistical sample included 145 faculty members and 873 students from the United States, Bulgaria, Moldova and Macedonia. Responses from the United States and Bulgaria were collected in the fall of 2002. Moldovan responses were collected in the spring of 2003 and Macedo- 
nian ones in the fall of 2003. The participants in the surveys were students and faculty members from four-year colleges in Bulgaria and the United States. Most participants were students and faculty members representing Colleges of Education. The U.S. educational institutions were from the Midwest, whereas in Bulgaria, the respondents worked at or attended major Bulgarian universities in the capital and in the country. The Moldovan respondents represented a large university in the country. Macedonian respondents hailed from the one university in the capital Skopje. Similar data for a longitudinal research was collected in the fall of 2007 from Bulgaria and the U.S., which will be included in future research.

The following variables were employed in the study (generally as independent variables): Country (four levels, the U.S., Bulgaria, Macedonia, and Moldova), Status (divided into students and faculty groups), and Department/Major (science/math/technology versus education). The following dependent variables were employed in analyses: (1) satisfaction with technology and the institution and comfort with technology use; (2) technology use among different departments at the institution; (3) use of various online communication techniques; (4) online assessment and evaluation; (5) role of the library; (6) access to technology.

In most cases, several separate analyses wee conducted in order to address a single research question. In a first section, differences between advanced (represented by USA data) and emerging societies (represented by Bulgaria and the other Eastern European countries) in satisfaction with and use of technology were examined. Via the same set of analyses, differences between students and professors were also examined as were interaction effects. In a second section, the use of technology among students and faculty of different university majors was examined. In the third, the use of online communication modalities was examined. In addition, the role of libraries and access to computer labs were analyzed. The forth and last section included supplementary, descriptive information such as age, gender, and free-text opinions, which can supply useful suggestions for future refinement of the research and exploration of ideas about educational technology and its uses.

Surveys were distributed both as paper copies and online. Online surveys are available in English for faculty: http://web.stcloudstate.edu/pmiltenoff/survey/survey_f.html and students: http://web.stcloudstate.edu/pmiltenoff/survey/survey_s.html; in Bulgarian for faculty: http://web.stcloudstate.edu/pmiltenoff/survey/anketa_p.html and students: http://web.stcloudstate.edu/pmiltenoff/survey/anketa_s.html; in Russian for faculty: http://web.stcloudstate.edu/pmiltenoff/survey/survey_moldova/survey_f_russian.html and students: http://web.stcloudstate.edu/pmiltenoff/survey/survey_moldova/survey_s_russian.html; and in Macedonian for faculty: http://web.stcloudstate.edu/pmiltenoff/survey/macedonia/survey_m_f.html and students: http://web.stcloudstate.edu/pmiltenoff/survey/macedonia/survey $\mathrm{m}$ s.html

Responses from paper surveys were entered in MS Excel spreadsheet and imported into the SPSS statistical package. All data were processed via SPSS. Data in tables is available upon request.

The statistical process included non-parametrical method (Chi square) and where appropriate ttests. Independent samples T-tests were run because the comparison was not made on matched sets of respondents, nor did comparisons fit a within-subjects or repeated measures type design (Huck, 2004). When sets of correlated tests are run, Type I error rates are artificially increased on a family-wide basis. To control for the family-wide error rate problem, a more stringent limit of 0.02 was employed using Bonferroni's adjustment (adjusted alpha $=\alpha / \mathrm{k}-1$, where $\mathrm{k}$ is the number of tests in a family (Huck, 2004). 


\section{Results}

Figure 1 displays a younger, in average, American faculty compared to their colleagues in the three Eastern European countries. While the first data suggestion might be that a younger faculty is more prone to be technology-savvy, a study at University of Michigan at Ann Arbor reveals specifics and uniqueness of the American faculty members (Berger, 2007). American students are also unique in comparison with their Eastern European counterparts, given the impressive number of "returning" or "life-long" students. The first assumption for the student pool might be that the American students will be slower in accepting technology-- compared with their "Millennial" Eastern European counterparts.
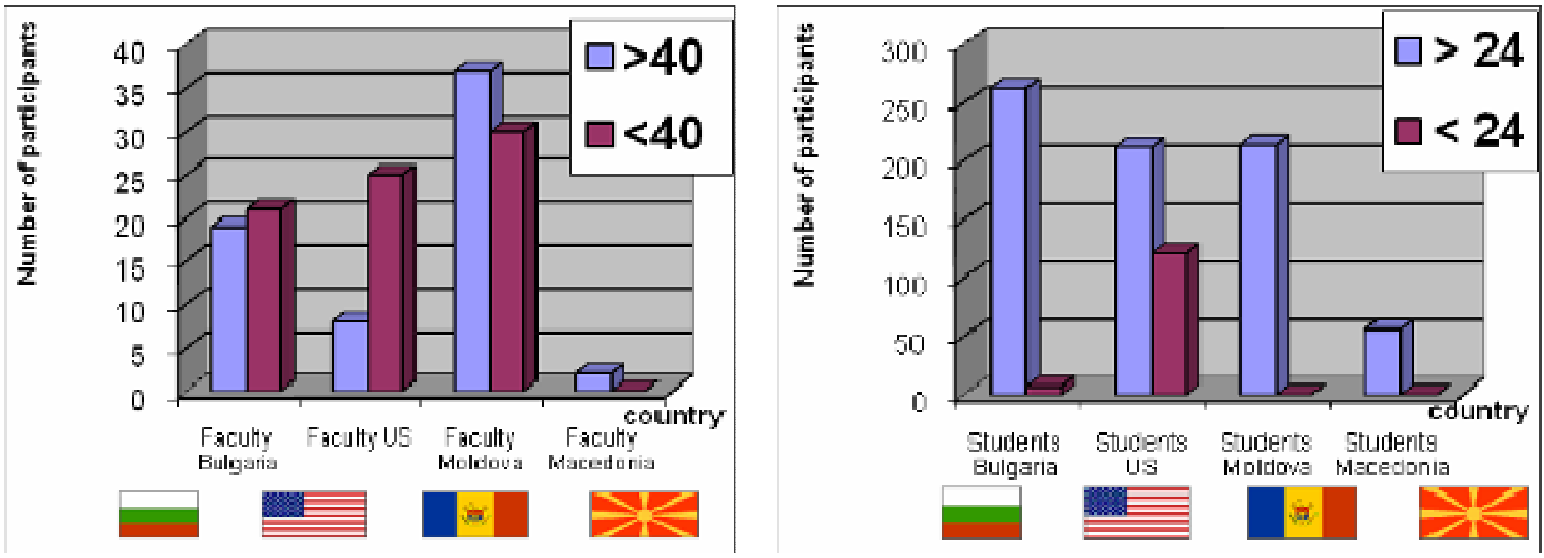

Figure 1. Age of faculty members and students

The assumptions that one can make by studying faculty and students age from both sides of the Atlantic are tested by a survey organized into several categories.

\section{Technological State of Institutions}

Each of the five items for the "state of technology" proved statistically significantly different between the American and the East European respondents (Figures 2 and 3). The difference applies for both faculty members and students and it is worth noticing that within country, students versus faculty members' answers are also significantly different.

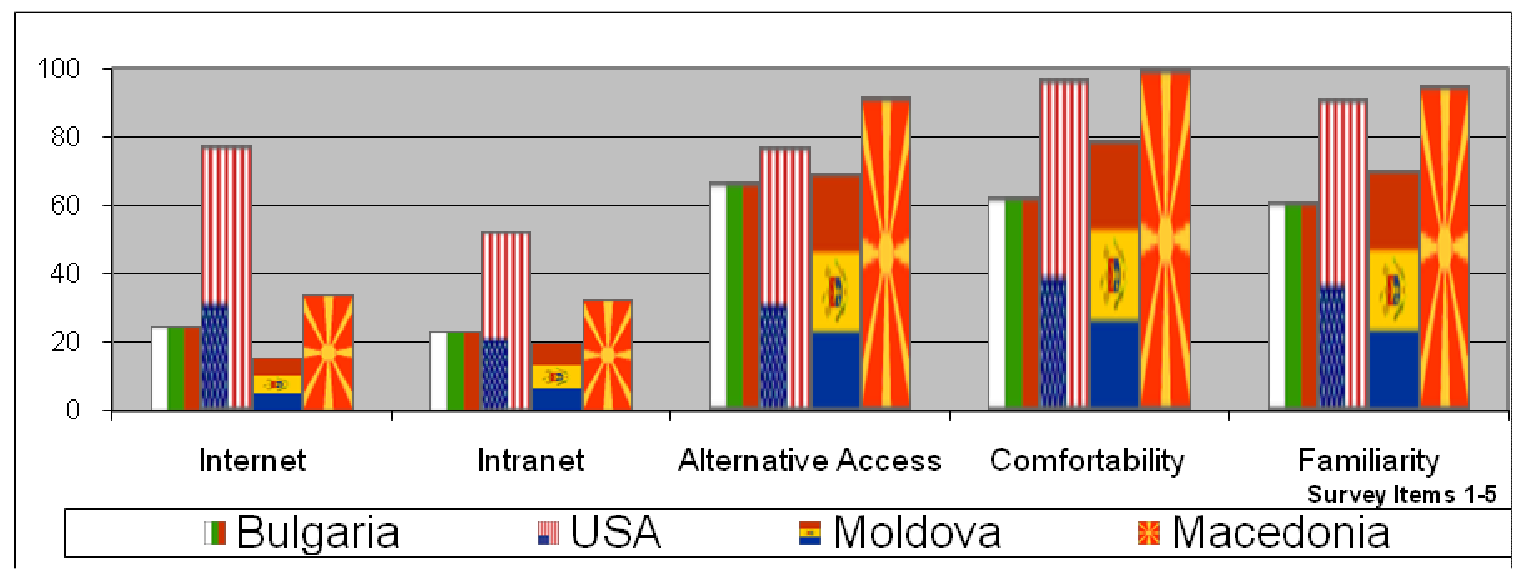

Figure 2. Percent expressing positive attitude toward aspects of technology use - students 


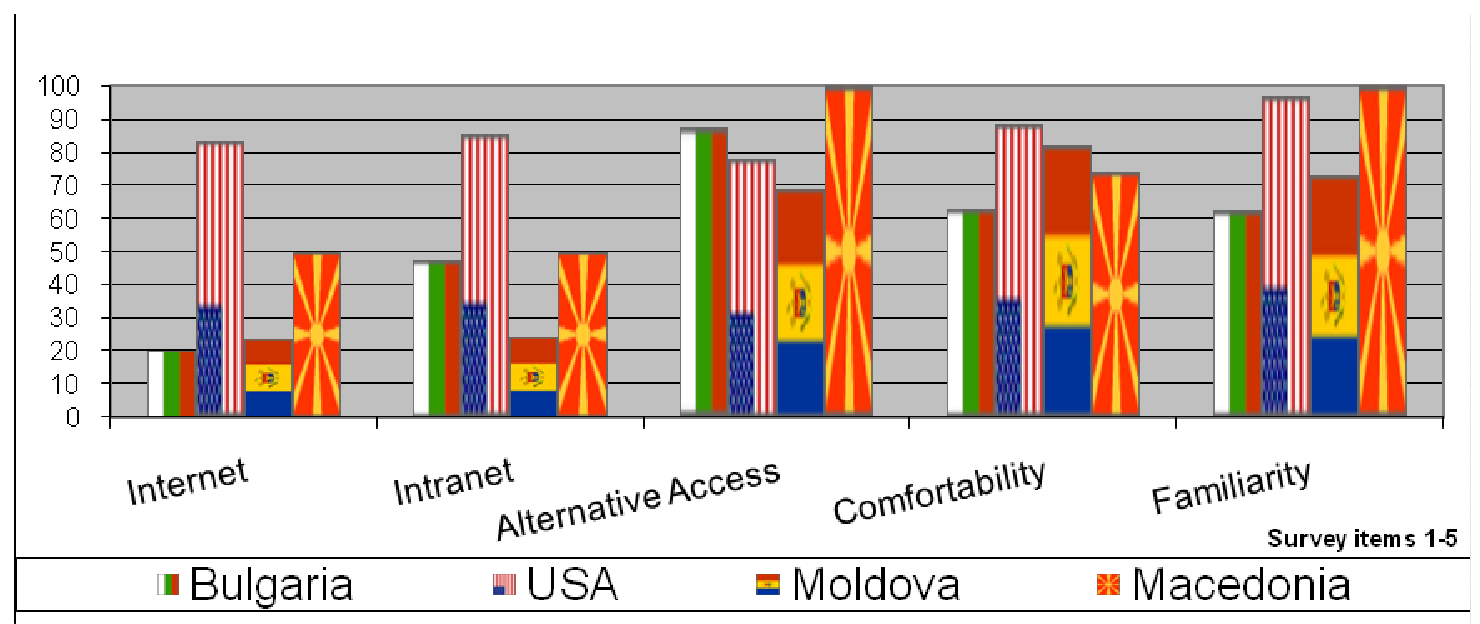

Figure 3. Percent expressing positive attitude toward aspects of technology use - faculty

The data from the survey confirms the literature sources cited in our introduction (Бюлетин на $H A O A, 2002$, p. 399). An obvious discrepancy exists between the technological status (quality of Internet and Intranet connectivity) at U.S. universities on one hand and the Eastern European educational institutions on the other. However, as item 3 from the survey shows, based on the opportunity for alternative access, Eastern European respondents are able to gain technological "comfort-ability" and familiarity at rates equal to or exceeding their American counterparts.

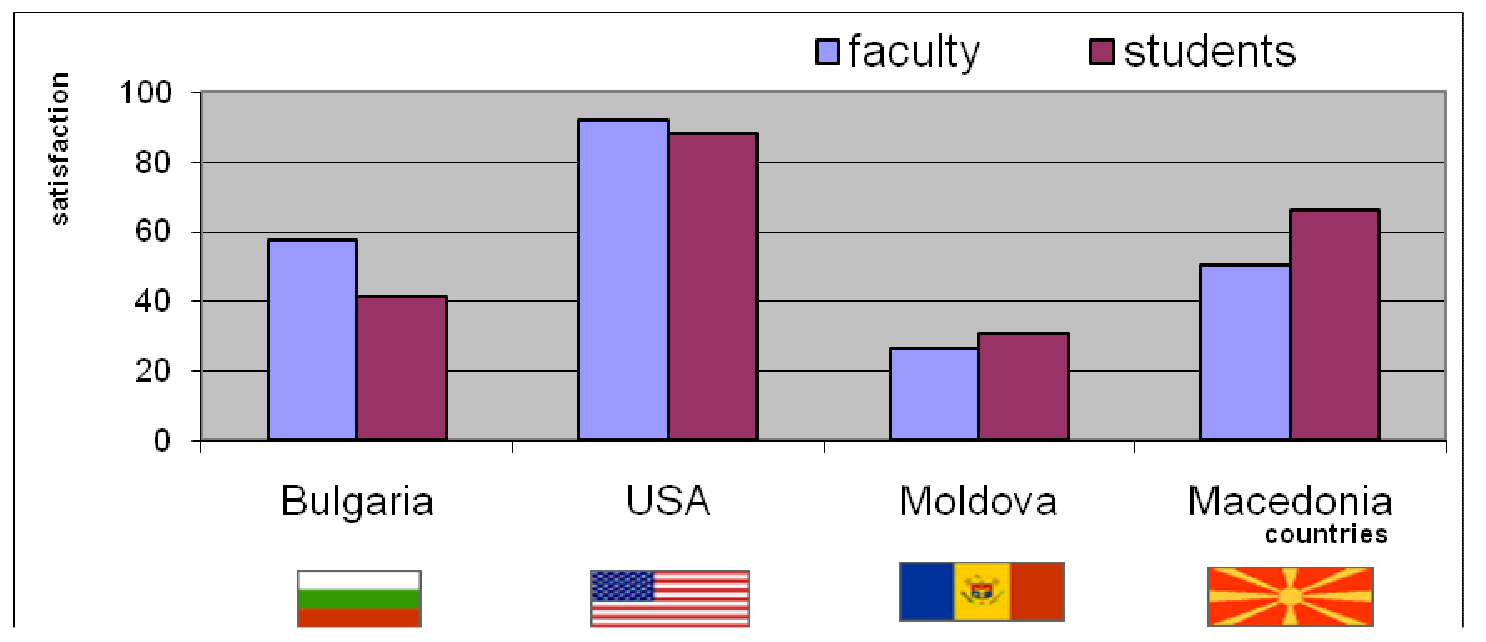

Figure 4. Faculty versus student satisfaction with technology by country

A comparison between the "satisfaction" levels of faculty versus students is displayed in Figure 4. One interesting and unexpected outcome is that the satisfaction between faculty and students does not vary significantly across countries. It was expected that the satisfaction rate of the U.S. respondents will be higher. The fact that the level of satisfaction among the respondents from the Eastern European countries vary significantly across status designations is worth further exploration. In 2003, Balti University in Moldova was still not connected to the fiber-optic Internet connection in town, which can be one reason for the low level of satisfaction. 


\section{Use of the Computer Lab at the Educational Institutions among Different Majors}

The statistical analyst employed t-tests for five items reflecting computer lab usage and educational applications. Means and standard deviations were employed descriptively. The difference between the U.S. and the other three countries connectivity was statistically significant.

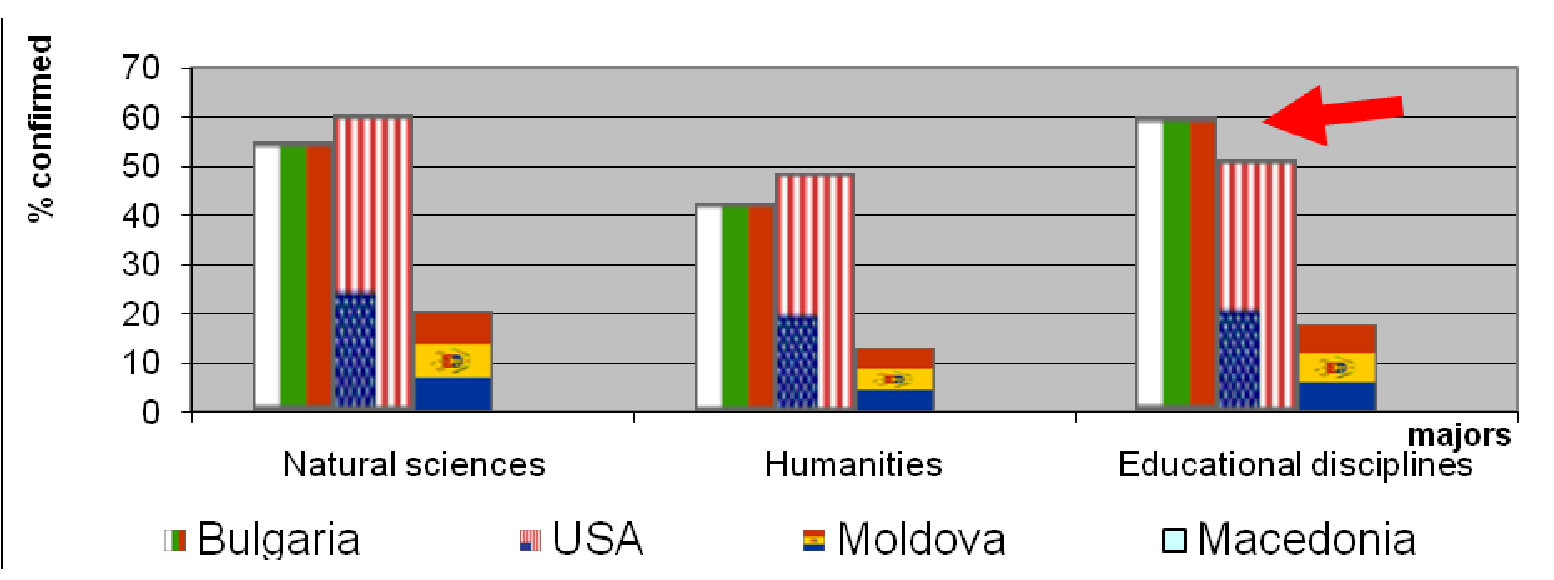

Figure 5. Percent of faculty members reporting use of computer lab by country and discipline area (zero for Macedonian faculty respondents)

Considering the literature findings outlined in the introduction (Report e-Bulgaria, 2006) and the results from "lab use" and satisfaction items, it is not surprising that both American faculty members and students tended to use computer labs in the educational process at rates higher than their Eastern European counterparts. On the other hand, Bulgarian faculty members in education and Moldovan natural sciences students surpassed their American counterparts in lab use; a fact worth further investigation.

Computer lab use differed by discipline across countries. American students majoring in education have the highest rate of computer lab usage in comparison with students representing other majors. It is probably the case that in 2002, students in the natural sciences tended to own computers whereas higher numbers of education majors did not. Further investigation on such digital inequality among majors can bring clarity and improve the plan of action for general application of technology in education.

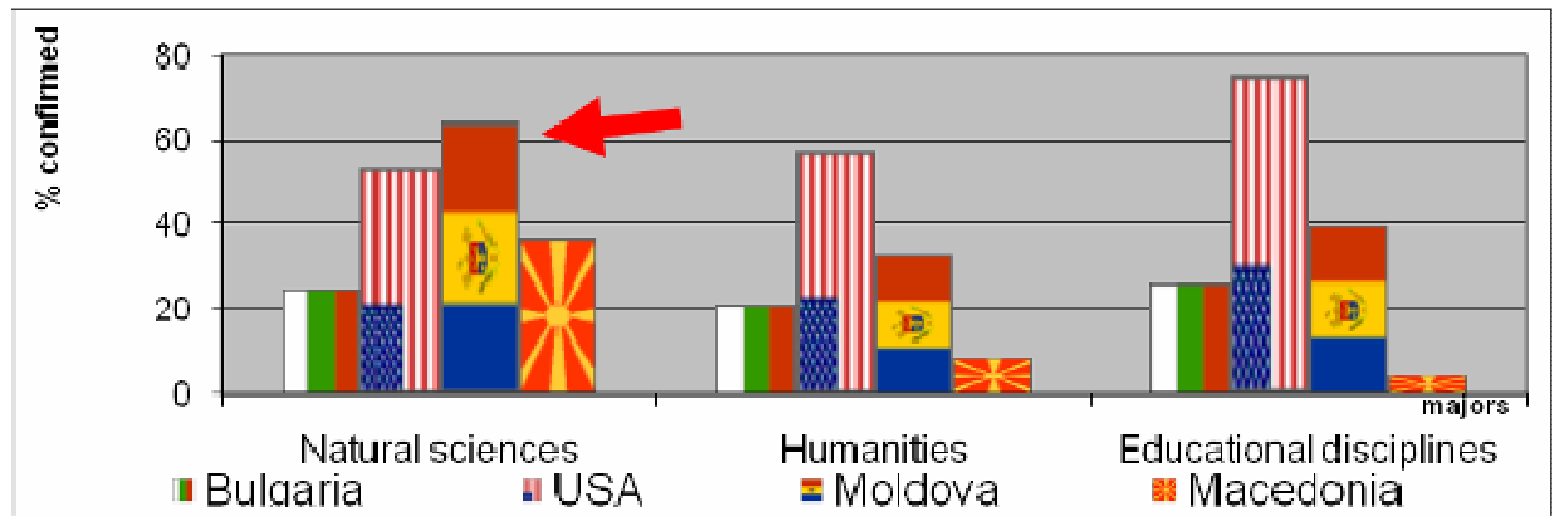

Figure 6. Percent of students reporting use of computer lab by country and discipline area 


\section{Use of Online Communication in the Educational Process}

The statistical analysis employed t-tests for five items reflecting levels of online communication among faculty members and students. Means and standard deviation are employed as descriptive metrics in these analyses. The difference between the U.S. and the other three countries, taken together, was statistically significant.

For the year 2002, the five most popular types of electronic communication in academia were the following: email, chat, listservs, instant messaging and discussion lists. With the exception of email, however, the rest were scarcely used, even in the United States, where the state of technology was putatively more advanced. A red flag for the Eastern European countries is that faculty use of electronic communications is greater than that of students. Considering extant literature, it would be expected that students enjoy access to technology at higher rates and they are able to communicate online to a significant degree (Stephenson, 2002).

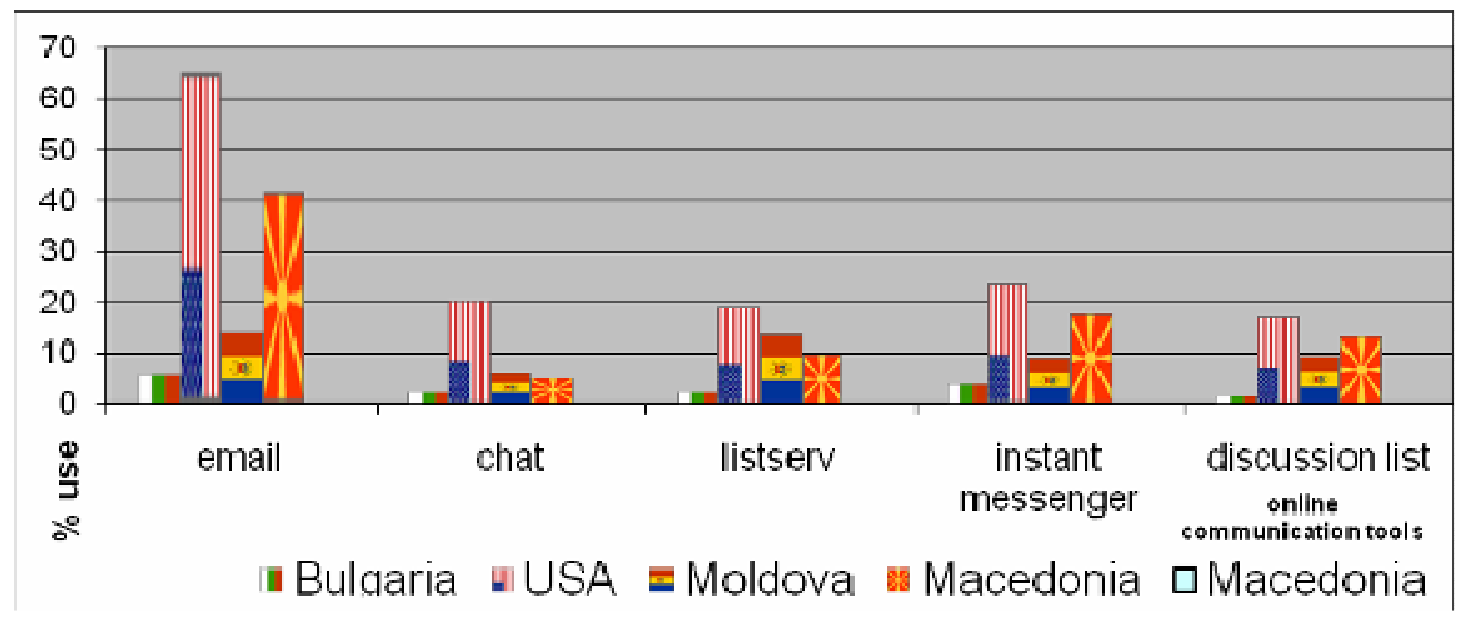

Figure 7. Percent of students reporting educational use of online communication technology

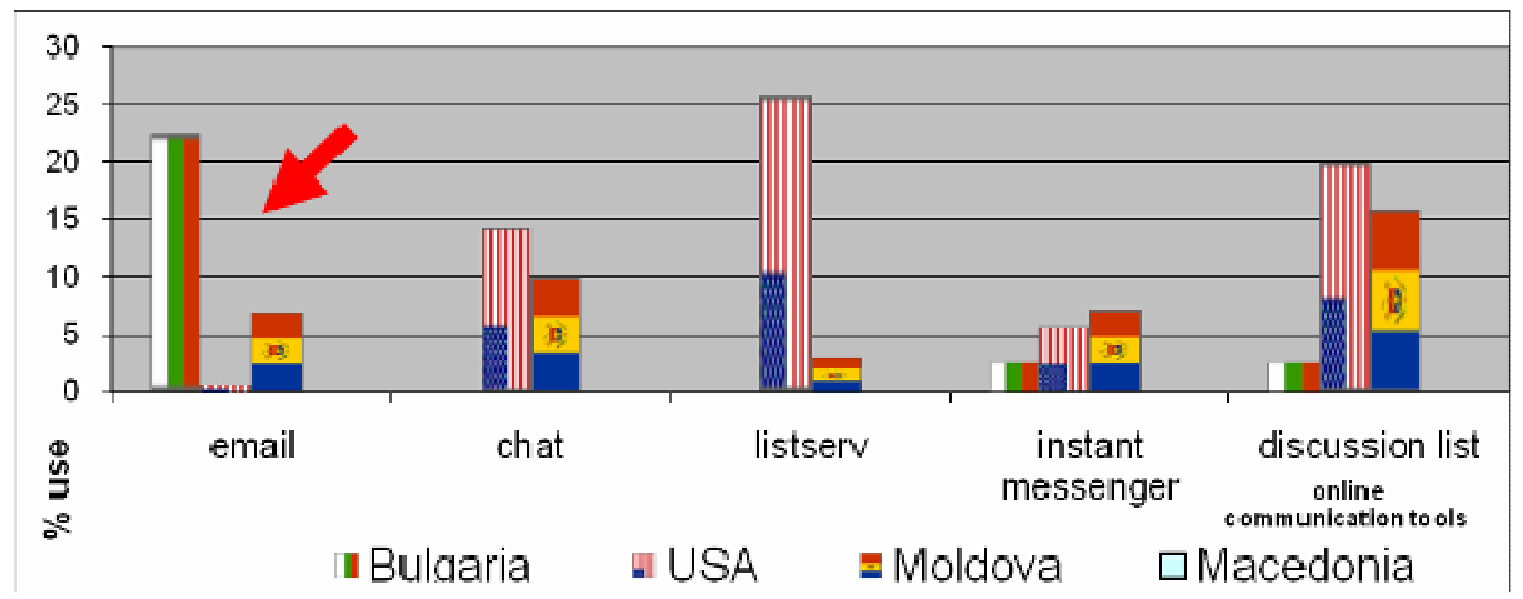

Figure 8. Percent of faculty reporting educational use of online communication

In 2002, the Eastern European faculty reported significantly higher use of instructional email then their American counterparts, whereas American students, as expected, are leading in email use. It is interesting to consider the interpretation of such a discrepancy, especially considering the fol- 
lowing facts: Email at present time is the official means of communication at most campuses in the US. Moreover, the fact that in 2006, American students asserted that email is no longer their favorite communication tool (Carnevale, 2006) and the results displayed in Figure 7 and 8 suggest that university administrators and faculty members might be slow in responding to students' needs, their choice of online communication technology for interaction in particular.

\section{Online Assessment and Feedback}

The results of the statistical analysis for items related to provision of feedback and assessment is displayed in Figure 9. While the Eastern European users are adjusting to the use of online communication tools for a feedback and interaction among faculty members and students, they certainly lag behind their American counterparts in provision of assessment. In 2002-2003, Course Management Systems (CMS) (Briefly on CMS:

http://en.wikipedia.org/wiki/Course_management_system) such as Blackboard/WebCT (http://www.blackboard.com/us/index.Bb?SERV1) were rapidly gaining popularity. One of the [very popular] modes of CMS is "Grades," which can explain the drastic difference in responses regarding assessment.

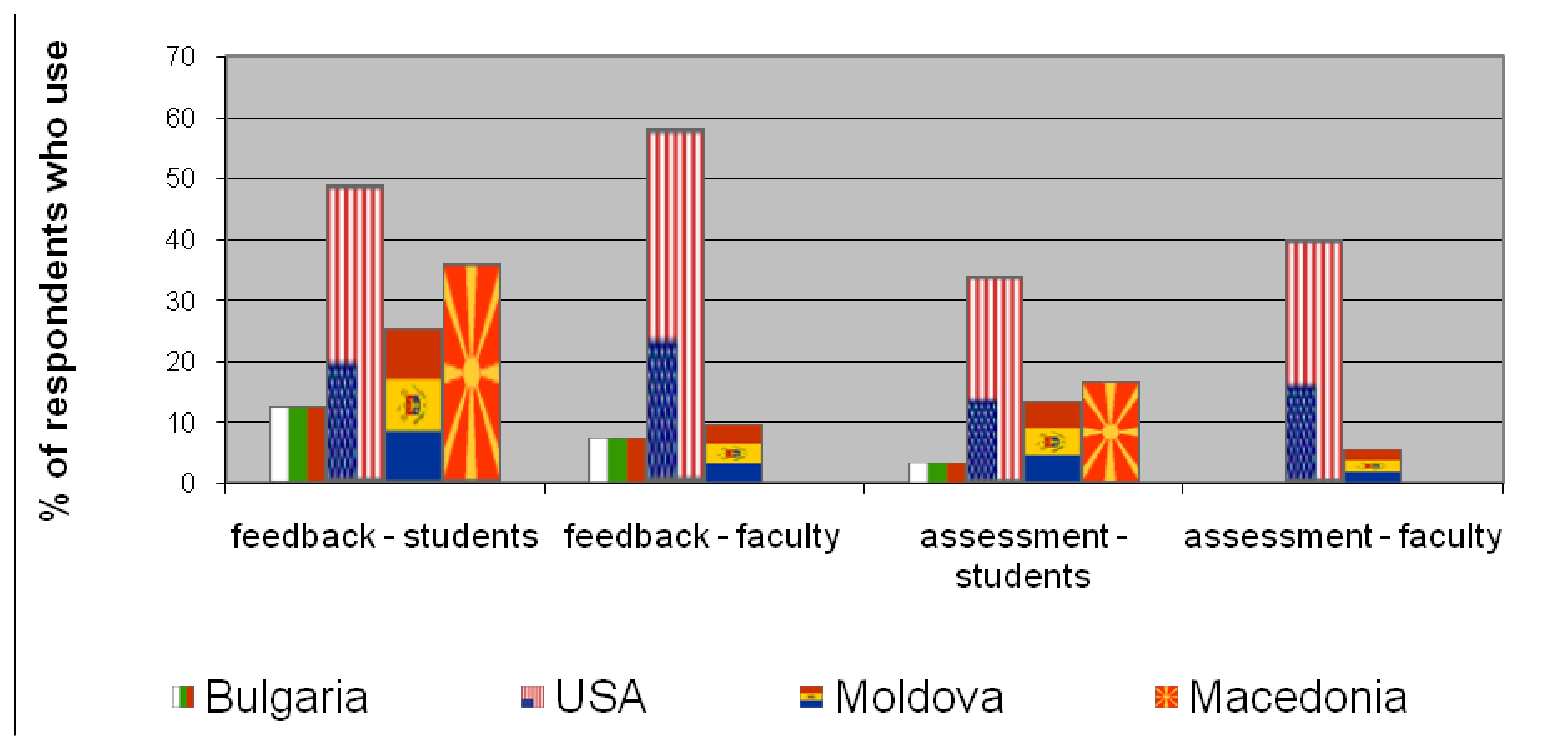

Figure 9. Use of online technology to provide feedback/assessment by country and status

The results reveal a low level of online assessment and feedback in education, though obviously U.S. results tend to rank higher, with the exception of e-mail. Standard benchmark for assessment and evaluation in online learning environments is needed for future comparisons of this type. CMS software is becoming popular outside of the United States, with the open source Moodle (http://moodle.org/), leading a long list of available software (Nagel, 2008). More importantly, CMS is recently not the only suitable and easy to use online assessment provider since asynchronous CMS as a concept is rapidly overshadowed by new e-conferencing tools (Briefly on econference tools: http://en.wikipedia.org/wiki/Webinar) (such as Elluminate [http://www.elluminate.com/], Adobe Connect [http://www.adobe.com/products/connect/], etc.), which allow synchronous interaction among faculty and students. 


\section{Role of the Library as Technology Provider}

Two important results emerge from the results displayed in Figure 10. One is the role of the library at the academic institution. The figure clearly shows that the opinion of faculty and students about their library in each country is very similar. Both students and faculty in Bulgaria evidenced very low opinion about the role of their library as technology provider, compared with their American counterparts, (both faculty and students) who see the library as a place where they can find technology support.

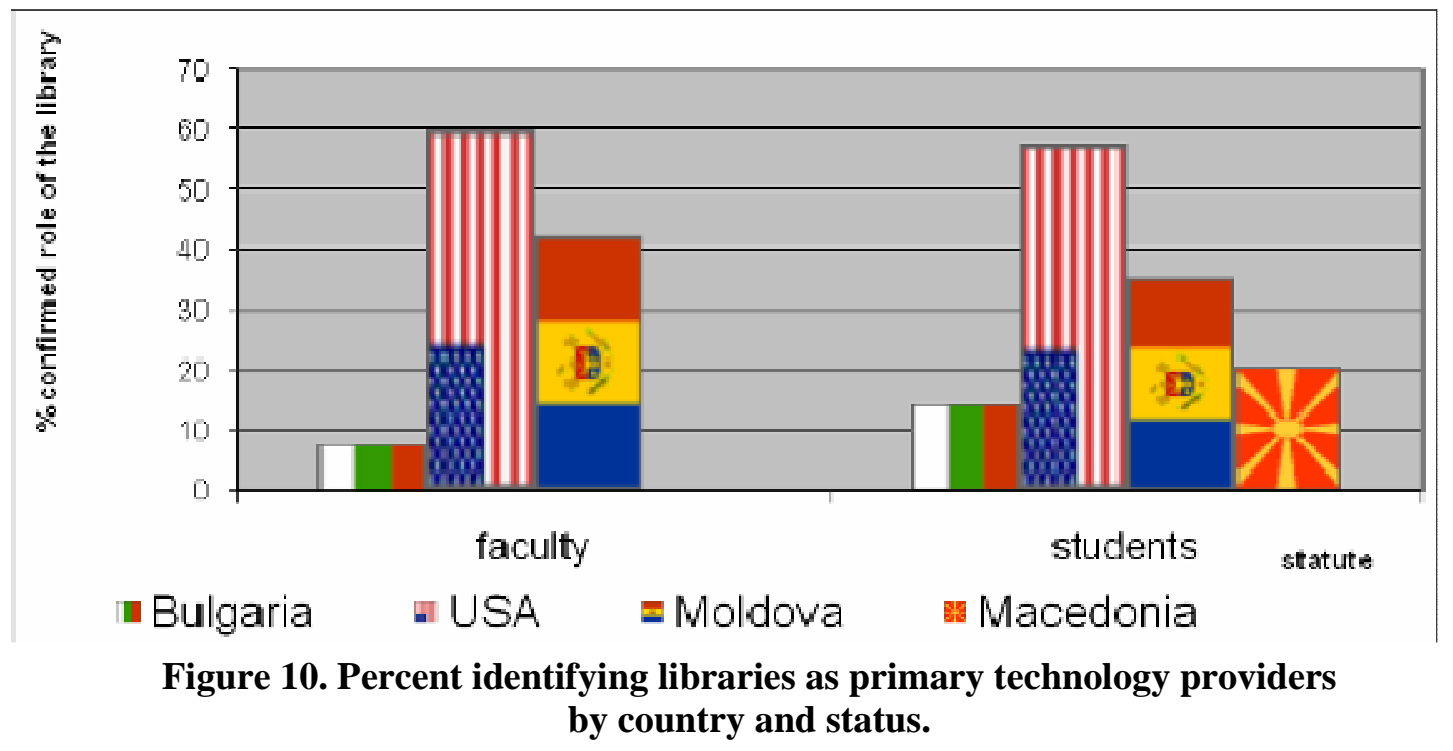

The second issue is the role of the academic library per se. Even at American educational institutions, results suggest that only $60 \%$ see the library as the technology center on campus. The changing role of the library as technology educator and provider is clearly stated by the American Library Association. On the other hand, a palpable and growing gap exists between library services and culture and respective expectations by the Millennial generation. (Briefly about the Millennials: http://en.wikipedia.org/wiki/Millennials, otherwise, Howe, N. \& Strauss, W. (2000). Millennials Rising: The Next Great Generation. New York: Vintage Books) (Thomas \& McDonald, 2006).) The results from the survey clearly shows that, with the exception of the faculty and students from the U.S. educational institutions, the other countries need to work hard on bringing the library and its staff to the requirements of the $21^{\text {st }}$ century as defined by the American Library Association (ALA)

(http://www.ala.org/ala/ourassociation/governingdocs/keyactionareas/educationaction/educationc ontinuing.htm).

ALA calls for libraries to turn into the technological hub on campus; a place which houses cutting-edge technology. Moreover, it is a place where librarians turn into technology leaders; the avant-garde that assists faculty members in the strenuous transition toward technology-based education. Such stance is recognized by the European Union's "Information Society" (http://ec.europa.eu/information_society/index_en.htm). However, while Eastern Europeans are familiar with this trend, Internet cafes, not the library, remain the place where young people access technology (Dimchev \& Miltenoff, 2006).

The issue of the library's role is further exacerbated by the "disconnection between library culture and the Millennial generation values" as title of article phrased by Thomas and McDonald (2006). Any further delay in turning the library into the campus technology hub and place where faculty 
and students can learn technology is pushing students away and slows down the whole academic world's acceptance of technology.

\section{Access to Computer Labs}

An item was developed via which information was requested about the temporal availability of the computer labs. As expected and shown on Figures 11 and 12, faculty members and students reported differential levels of access to technology that significantly influences the use of online technologies. Moreover, around-the-clock use of computer labs certainly produces a potential advantage for American students. Of course, this advantage depends upon at least two factors. First, the overall time of use should be controlled in future studies. Perhaps Eastern Europeans adjust their schedules and thus attain as many lab hours as their American counterparts. A second issue is that quality-of-use factors were not addressed by survey items. Again, the possibility exists that Eastern European students may use labs more strategically and intensively during available hours. Little educational advantage would accrue, for example, to American students playing computer games at 2:00 A.M. Also, assistance with technology and course content would probably overlap with lab hours (in assessment of learning impact). According to the results of the survey, however, remains the fact that American students have greater freedom in using technology then their Eastern European colleagues.

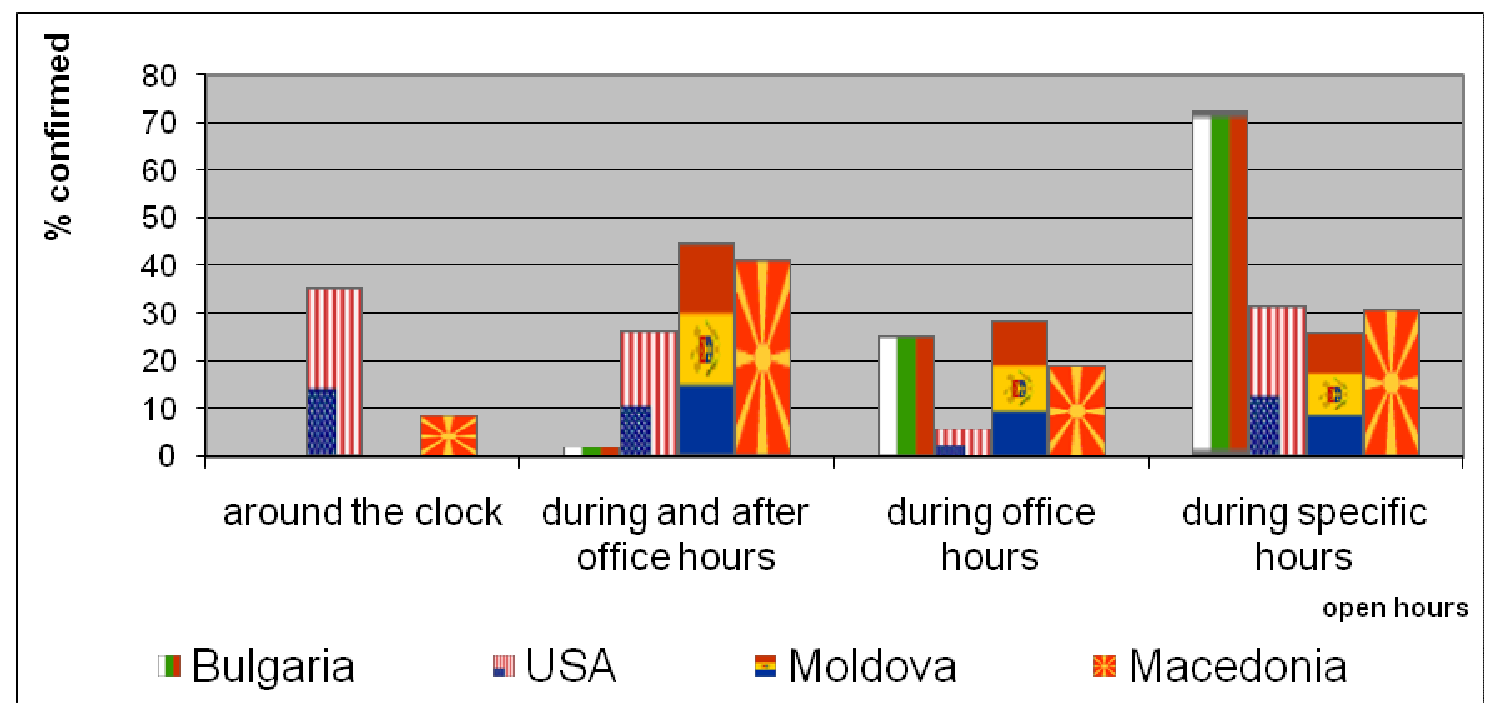

Figure 11. Percent of students reporting varying levels access to computer labs by country. 


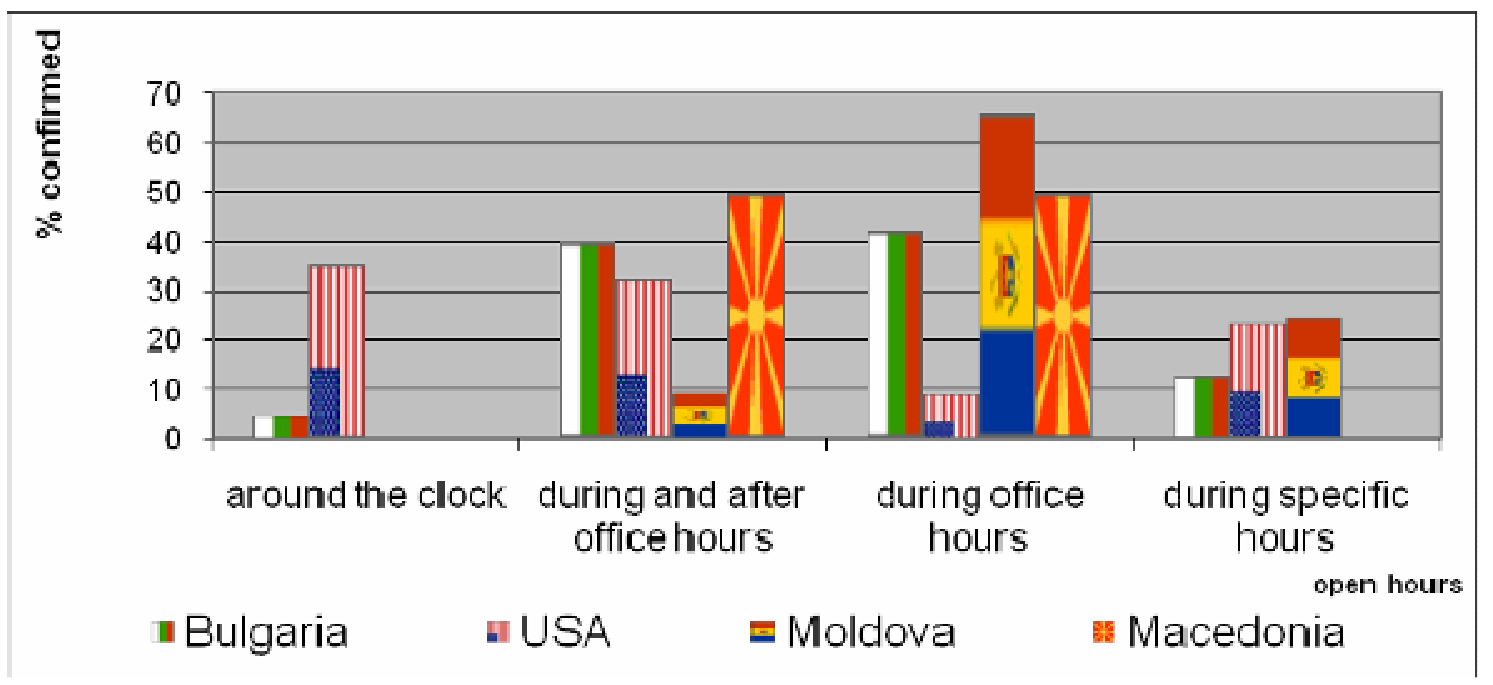

Figure 12. Percent of faculty reporting varying levels access to computer labs by country.

However, access issues may well be important and their resolution could reduce the digital divide between students in the U.S. and Eastern European counterparts. The evidence of this survey supports the idea that it is time to revise the administration and use of computer labs at the Eastern European educational institutions, whereas access of students to those facilities should be granted in unconventional and longer hours.

\section{Conclusions}

Online education is a global trend and is not solely a domain of developed countries. Online education may prove to open a venue for developing countries to educate their population more economically, in comparison with traditional "bricks-and-mortar" schools (Bollag \& Overland, 2001; Dhanarajan, 2001). Online interaction is a key factor for the success of online education. It increases students' motivation and as a result, boosts academic achievement and retention.

Based on the literature, a study was conducted comparing attitudes toward technology and online communication of faculty members and students representing several countries. A survey of educational institutions in the U.S. and three small Eastern European countries reveals expected outcomes: A digital divide exists between developed and developing countries. Eastern European countries lag behind in hardware and bandwidth availability and the faculty members and students are well aware of it. It is important to note that the structure of the faculty and student body in the United States and Eastern Europe varies significantly; this influence acceptance in technology in education can be an important topic for future research.

Here are the most significant findings of this study:

- Eastern European faculty and students use alternate access (e.g. Internet cafes, home computers) to make up the need for hardware and bandwidth.

- Eastern European faculty members' and students' satisfaction and comfort with technology is relatively strong, even in comparison these values with their North American counterparts.

- Education students use the computer lab, but not as often as do students from other disciplines. With the exception of the American students, Eastern European respondents lag behind (in lab use). 
- It appears likely based on current results that faculty members and administrators are not responding to the students' preferred modalities for online communication. Specifically, the use of email versus alternative communication tools.

- Online assessment is still used at relatively low rate, considering the technology and options available, even back in 2003.

- The library as a technology provider is an underused institution on campus.

- Administration of computer lab use in Eastern European universities can be improved by expanding hours and securing access during unconventional hours.

Two major recommendations based on the survey include revising and supporting the role of the academic library by administrators and faculty and striving to provide a 24/7 access to computer labs. It is also recommended that, in future investigations, the quality and intensity of student lab use during open hours and total hours spent in labs be collected as control variables.

Other recommendations include:

- Universities in Eastern European countries need to improve technology performance (Internet and Intranet).

- Educational students need to be provided with a matching access to computer labs as the students from other majors.

- Libraries must replace Internet cafes as convenient and secure places for young people.

- Future studies of lab use should include metrics related to learning outcomes and such control variables as effective use (study versus gaming, for example), strategic use (students scheduling use effectively during open sessions), and staffing patters (whether or not, or to what degree, technology and content assistance is available during open hours).

This study posed only two questions to measure faculty and student satisfaction in working with technology. A future research can consider other parameters to better evaluate levels of satisfaction (e.g., involve cross-cultural studies and psychology benchmarks to streamline and define precisely "satisfaction"). The improvement of faculty and students satisfaction can lead to a better and faster application of technology in education.

The findings from the survey also reveal unexpected outcomes: faculty and students at US institutions do not use the technology to its full potential. For example, it was discovered that computer labs in Eastern Europe remain dormant for the greater part of the week (evenings, nights and weekends); available online communication tools are not used to their potential, etc. The lessons learned from the motivational reasons of the Eastern European faculty and students can possibly help their American counterparts.

\section{References}

Bell, P. (2007, Summer). Predictors of college's student achievement in undergraduate asynchronous Webbased courses. Education, 127(4), 523-533.

Bennett, S., \& Lockyer, L. (2004, September). Becoming an online teacher: Adapting to a changed environment for teaching and learning in higher education. Educational Media International, 41(3), 231244.

Berger, C. F. (2007). The millennium student: And now, evidence for the millennial instructor! Educause Resource Center. Retrieved February 17, 2007 at: http://www.educause.edu/ELI071/Program/10825?PRODUCT_CODE=ELI071/SESS39

Bollag, B., \& Overland, M. A. (2001). Developing countries turn to distance education. Chronicle of Higher Education, 47(40), 29-31.Retrieved November 1, 2007, at: http://chronicle.com/weekly/v47/i40/40a02901.htm 
Burnett, K., Bonnici, L. J., Miksa, S. D., \& Joonmin, K. (2007, Winter). Frequency, intensity and topicality in online learning: An exploration of the interaction dimensions that contribute to student satisfaction in online learning. Journal of Education for Library \& Information Science, 48(1), 21-35.

Carnevale, D. (2006, October). E-mail is for old people. Chronicle of the Higher Education. 53(7). P. A27. Last accessed February 14, 2007: http://chronicle.com/weekly/v53/i07/07a02701.htm

Dhanarajan, G. (2001). Distance education: Promise, performance and potential. Open Learning, 16(1). 6168. Retrieved November 1, 2007 at: http://search.ebscohost.com/login.aspx?direct=true \&db=aph\&AN=4041530\&site=ehost-live

Dimchev, A., \& Miltenoff, P. (2006). Books, libraries, media and new information technologies: Seeking the balance. The new information technologies (NIT) and the risks for the coming generation. Proceedings of the International Scientific Conference "Children and Libraries," October 5-8, 2005, Belgrade, Yugoslavia. Retrieved Feb. 6, 2007 from http://web.stcloudstate.edu/pmiltenoff/ioc_2006/balance_nit.doc

Gould, M, \& Padavano, D. (2006, May). 7 ways to improve student satisfaction in online courses. Online Classroom, 1-2.

Green, M. C., Hilken, J., Friedman, H., Grossman, K., Gasiewski, J., Adler, R., \& Sabini, J. (2005). Communication via instant messenger: Short- and long-term effects. Journal of Applied Social Psychology, 35(3), 445-462.

Huck, S. W. (2004). Reading statistics and research. (4th ed.). Boston, MA: Pearson/Allyn and Bacon.

Kawachi, P. (2003). Initiating intrinsic motivation in online education: Review of the current state of the art. Interactive Learning Environments, 11(1), 59-82.

Lee, J., Carter-Wells, J-A., Glaeser, B., Ivers, K., \& Street, C. (2006). Facilitating the development of learning community in an online graduate program. Quarterly Review of Distance Education, 7(1) 1333.

Nagel, Dave. (2008, January). Open source poised for surge in education. THE Journal. Last retrieved January 30, 2008 at: http://www.thejournal.com/articles/21900

National Evaluation and Accreditation Agency's Newsletter. Бюлетин на HAOA((2002). 4. Sofia.

Read, B. (2007). A digitally isolated Africa. The Wired Campus of Chronicle of Higher Education. Retrieved October 26, 2007, from http://chronicle.com/wiredcampus/article/?id=2447

Report e-Bulgaria. Доклад е-България. (2006). Фондация «Приложни изследвания и комуникации». София. Retrieved February 15, 2007 at: http://www.daits.government.bg/projects.php

Schrum, L., Burbank, M. D., \& Capps, R. (2007, July). Preparing future teachers for diverse schools in an online learning community: Perceptions and practice. Internet \& Higher Education, 10(3), 204-211.

Stephenson, J. (Ed.). (2002). Teaching \& learning online: new pedagogies for new technologies. London: Kogan Page.

Thomas C., \& McDonald, R. (2006). Disconnects between library culture and millennial generation values. Educause Quarterly, 26(4). Last retrieved February 5, 2007 at: http://www.educause.edu/apps/eq/eqm06/eqm0640.asp?print=yes

Young, A., \& Norgard, C. (2006,). Assessing the quality of online courses from the students' perspective. Internet \& Higher Education. 9(2), 107-115. 


\section{Biographies}

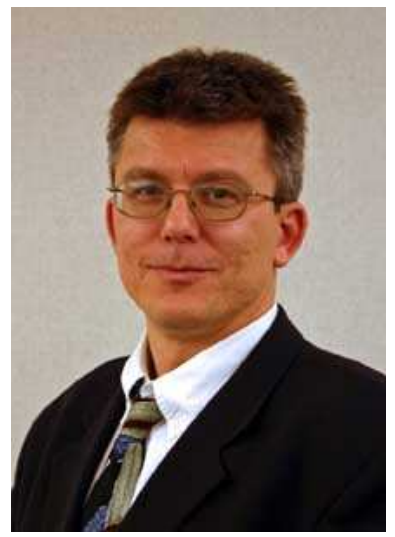

Plamen Miltenoff, MLIS, is information specialist at Learning Resources \& Technology Services (LR\&TS) of St. Cloud State University (SCSU) in St. Cloud, Minnesota. Plamen Miltenoff has graduate degrees from universities in Bulgaria, Austria, and from University of Florida. He is completing his Ph.D. with Shoumen University in Bulgaria and a separate terminal degree in education with University of North Dakota. His professional interests include new technologies, Web development and multimedia, interactive and Web development in education. Plamen Miltenoff is the liaison of the library (LR\&TS) to College of Education at SCSU.

John Hoover, Ph.D., served as the Director of the Bureau of Educational Services and Applied Research at the University of North Dakota from 1997 to 2001. He recently accepted an appointment at St. Cloud State University, his alma mater, in Special Education; where he was elected Chair in January of 2003. Hoover's research interests lie in bullying and child-on-child aggression; he has published three books and over 40 research papers, book chapters, reviews, and study guides in the area. Hoover has worked with over 20 school districts in the past five years in violence reduction programs and has evaluated several violence prevention efforts. He is also interested in transition services for students with disabilities, rural special education service delivery, and the application of cognition to interpersonal problem solving in youth with disabilities.

Galin Tzokov, Ph.D., is an Associate Professor of Pedagogy and Educational Management at the Department of Pedagogy of the Plovdiv University in Plovdiv, Bulgaria. Tzokov served as a Vice-President of the Educational Commission Municipal Council and as a Chairman of the Municipal School Board of the city of Shumen. He is a member of the Bulgarian Association of Scientists, the Bulgarian Pedagogical Society and the National Center for Distance Education in Bulgaria. Tzokov's interests include educational management, management of private schools and educational legislation. He works also in the field of information technologies in education and distance education. 